\title{
Thiabendazole adsorption on montmorillonite, octadecyltrimethylammonium- and Acremonium sp.-loaded products and their copper complexes
}

\author{
Martina Gamba ${ }^{\text {a }}$, Melisa Olivelli ${ }^{\mathrm{b}}$, Juan M. Lázaro-Martínez ${ }^{\mathrm{c}}$, Gisella Gaddi ${ }^{\mathrm{a}}$, Gustavo Curutchet ${ }^{\mathrm{b}}$, \\ Rosa M. Torres Sánchez ${ }^{\mathrm{a}, *}$ \\ ${ }^{a}$ CETMIC-CONICET-CCT La Plata, CICBA, Camino Centenario y 506, (1897) M. B. Gonnet, Argentina \\ ${ }^{\mathrm{b}}$ Escuela de Ciencia y Tecnología e Instituto de Investigación e Ingeniería Ambiental, Universidad Nacional de San Martín, Buenos Aires, Argentina \\ ' Universidad de Buenos Aires, IQUIFIB-CONICET, Facultad de Farmacia y Bioquímica, Departamento de Química Orgánica, Junín 956 (1113), CABA, Argentina
}

\section{H I G H L I G H T S}

- $\mathrm{Cu}^{2+}$-loaded bio and organomontmorillonites were efficient TBZ adsorbents.

- $\mathrm{Cu}^{2+}$-thiabendazole complexes were formed in the interlayer of montmorillonite.

- Low leaching values attained from $\mathrm{Cu}^{2+}$ and TBZ, suggested its use in wastewater treatment.

\section{A R T I C L E I N F O}

\section{Article history:}

Received 9 January 2017

Received in revised form 9 March 2017

Accepted 10 March 2017

Available online 11 March 2017

\section{Keywords:}

Montmorillonite

Organo-montmorillonite

Bio-montmorillonite

Thiabendazole- $-\mathrm{Cu}^{2+}$ complex

Adsorption
G R A P H I C A L A B S T R A C T

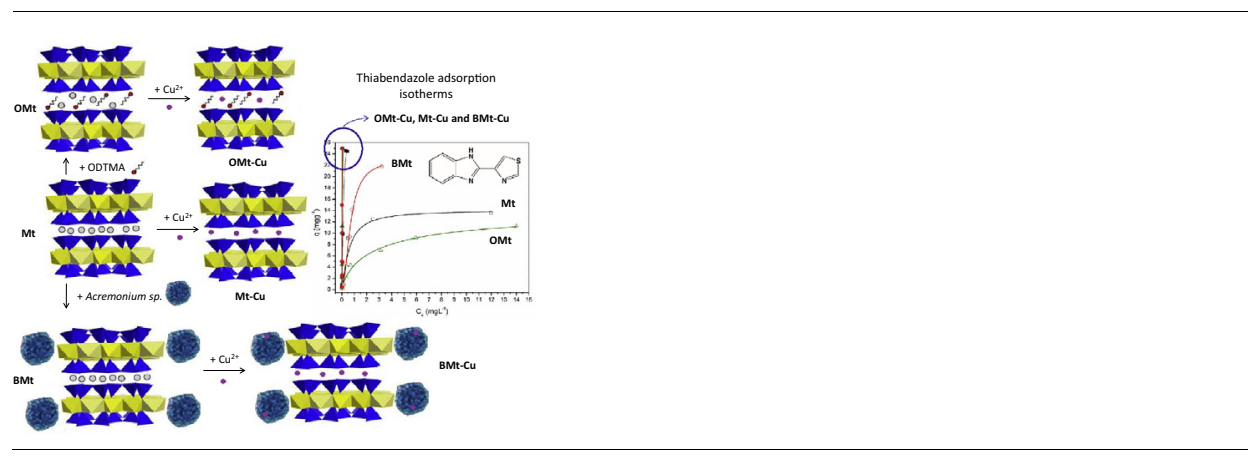

A B S T R A C T

This study is a preliminary approach to develop novel montmorillonite (Mt) based adsorbents for removing inorganic and organic contaminants in a step-like process. Biomass (fungi) and surfactant (octadecyltrimethylammonium bromide) modified montmorillonites (BMt and OMt, respectively) were obtained. In a prior step, $\mathrm{Cu}^{2+}$ was loaded into Mt, BMt and OMt. In a second step, the materials (Mt, Mt-Cu, BMt, BMt-Cu, OMt, OMt-Cu) were used as thiabendazole (TBZ) adsorbents. TBZ adsorption isotherms were performed, and Langmuir, Freundlich and Langmuir-Freundlich mathematical models were evaluated. TBZ removal efficiency of the materials was also tested using three adsorbent dosages.

The adsorbents and TBZ-adsorbed products were characterized by X-ray diffraction and thermal analysis, and by electron paramagnetic resonance (EPR) and solid-state nuclear magnetic resonance measurements (ss-NMR). To determine the subsequent arrangement of the adsorption products, leaching experiments were also conducted.

In the BMt sample, TBZ adsorption was enhanced compared to the raw Mt sample. An opposite behaviour was observed for OMt samples. All the $\mathrm{Cu}^{2+}$-loaded materials showed better TBZ removal efficiencies than the same materials without $\mathrm{Cu}^{2+}$. Furthermore, $\mathrm{Cu}^{2+}$ chelation through the imidazolic and thiazolic nitrogen atoms of TBZ in all $\mathrm{Cu}^{2+}$-loaded samples allowed TBZ and $\mathrm{Cu}^{2+}$ to be resistant to migration in environmental leaching conditions.

(ㄷ) 2017 Elsevier B.V. All rights reserved.

\footnotetext{
* Corresponding author.

E-mail addresses: martina.gamba@cetmic.unlp.edu.ar (M. Gamba), rosats@cetmic.unlp.edu.ar (R.M.T. Sánchez).
} 


\section{Introduction}

Thiabendazole (TBZ) is a benzimidazolic derivate compound, used mainly in agriculture to control mould, blight and other fungi that cause diseases in fruits and vegetables [1]. The high amount of TBZ used as post-harvest fungicide leads to water pollution through effluents from fruit packing plants. It represents a major environmental concern since it exhibits toxicity to animals, causing liver and intestinal disorders [2].

Adsorption is a widely studied process used to remove contaminants from aqueous effluents, where montmorillonite (Mt) clays have been largely studied as adsorbent of different contaminants [3-6]. The main reasons that turn Mt into an important adsorbent are its external negative surface charge - which makes it particularly useful to remove cationic compounds from water - and its large total specific surface - which allows concentrating a high amount of molecules and ions at both outer and inner surfaces. These surfaces use two different mechanisms to adsorb cationic compounds; for the inner surface, the cation exchange mechanism with $\mathrm{Na}^{+}$or $\mathrm{Ca}^{2+}$ raw interlayer cations has been indicated, while for the outer surface a $\mathrm{pH}$ dependent electrostatic mechanism with silanol and aluminol groups has been inferred by electrostatic measurements [7].

Organic intercalation into montmorillonite is usually proposed to enhance its adsorption capacity towards organic compounds [8-10]. Specially, when organic cations such as alkylammonium salts are used to exchange the inorganic cations of the raw clay interlayer, organo-montmorillonites are generated, promoting both chemical and structural changes. For instance, the basal space increases by entrance of organic cations in the interlayer space. The organophilic character becomes organophobic due to the disappearance of the hydration sphere related to the interlayer inorganic cations, evidenced by thermal analysis [11]. Besides, the negative external electric charge of Mt decreases or reverses to positive, trough the partial neutralization of permanent charges due to organic cations loading [12]. Furthermore, the swelling behaviour and the specific surface area of the clay decrease, which would allow an easier separation of the adsorbent from water by coagulation. These advantages have made organo-montmorillonites a material widely tested for the removal of organic pollutants from wastewater [7-8].

There is a lack of reports about TBZ adsorption onto organomontmorillonites, while its adsorption onto Mt and pillared Mt clays has been already studied [13,14]. Roca Jalil et al. [10] reported maximum TBZ amounts (Langmuir parameter) of $11.91 \mathrm{mg} / \mathrm{g}$ adsorbed onto Mt and an improvement of up to $63.87 \mathrm{mg} / \mathrm{g}$ for those adsorbed onto the respective aluminium pillared sample [14]. The ability of thiabendazole to coordinate transition metal ions through the imidazolic and thiazolic nitrogen atoms $[15,16]$ suggests that the incorporation of a transition metal cation in the adsorbent structure would further improve TBZ removal efficiency.

Copper is a transition metal usually found in mining, industrial and agricultural effluents. The International Programme on Chemical Safety (IPCS) stated that although the acceptable upper limit of copper for oral intake in adults is uncertain, it is likely to be in the range of several mg per day [17]. In order to obtain the acceptable limit of copper in the mentioned effluents, different physical or chemical treatment processes have been used. Among them, copper adsorption on clays, and particularly on montmorillonites, is a deeply studied method to remove it from aqueous media [1821] taking advantage of copper species bonding capability on permanent (interlayer or inner) and $\mathrm{pH}$ dependent (edge or outer) charge sites [22]. In addition, biosorption technology is recognized as a potential alternative method among conventional metal retention techniques where the main interactions involved in adsorption are those of functional groups on the cell wall structure of microorganisms with the contaminants. This process uses living, dead, pretreated or immobilized forms of biological cells such as bacteria, fungi, yeasts and algae as sorbent materials. In particular, the immobilized forms of biosorbent materials are more convenient in practical applications because of their mechanical strength, anti-degradability, physical morphology and chemical stability, as well as regeneration capacity [23].

The aim of this work was to evaluate different materials derived from Mt as TBZ adsorbents and study whether their performance changed when $\mathrm{Cu}^{2+}$ was present in their structure. The Mt derived materials were an octadecyltrimethylammonium (ODTMA) exchanged Mt (OMt) and an immobilized biosorbent material (fungi-loaded Mt, BMt). Organo-montmorillonites were chosen due to the possible improvement of organic species adsorption and their ease of separation from water [12], whereas BMt was selected taking into account its ability to remove heavy metal cations from water [24]. These materials (OMt, BMt and Mt) were first loaded with $\mathrm{Cu}^{2+}$ (OMt-Cu, BMt-Cu and $\mathrm{Mt}-\mathrm{Cu}$ ) and their TBZ adsorption capacity was evaluated. The successful use of these materials and methodology would also allow consecutive adsorption steps for wastewater treatments where metal cations and fungicides coexist. Although thiabendazole is one of the most widely used post-harvest fungicides in fruit production, there are other imidazole or benzimidazole fungicides (eg imazalil, carbendazim, methyl thiophanate, etc.) that could also be coordinated with $\mathrm{Cu}^{2+}$, to which the results of this work could be extended.

In order to compare the adsorbent performance, adsorption isotherms were done, and removal efficiency was evaluated at different solid dosages. To identify the surface adsorption sites involved, the adsorbents and TBZ-adsorbed products were characterized by $\mathrm{X}$-ray diffraction (XRD), thermal analysis, electron paramagnetic resonance (EPR), and solid-state nuclear magnetic resonance measurements (ss-NMR). Furthermore, in order to establish the subsequent disposal of the adsorption products, leaching experiments were performed.

\section{Materials and methods}

\subsection{Materials}

A Patagonian (Rio Negro province, Argentina) montmorillonite (Mt) sample, provided by Castiglioni Pes y Cia., was used as received. The main properties of Mt are: isoelectric point $($ IEP $)=$ 2.7, specific surface area $(\mathrm{SSA})=34.0 \mathrm{~m}^{2} / \mathrm{g}$, total specific surface area $($ TSSA $)=621 \mathrm{~m}^{2} / \mathrm{g}$ [25], and cation exchange capacity $(\mathrm{CEC})=$ $0.8250 \pm 0.0007 \mathrm{mmol} / \mathrm{g}$ clay [12]. The XRD and chemical analyses indicated that the raw sample contained $\mathrm{Na}-\mathrm{Mt}(>86 \%)$ with quartz and feldspars as minor phases. The structural formula obtained from the chemical analysis of purified $\mathrm{Mt}$ was: $\left[\left(\mathrm{Si}_{3.89} \mathrm{Al}_{0.11}\right)\left(\mathrm{Al}_{1.43} \mathrm{Fe}_{0.28}^{3+} \mathrm{Mg}_{0.30}\right) \mathrm{O}_{10}(\mathrm{OH})_{2}\right] \mathrm{Na}_{0.41}^{+}$[25].

Octadecyltrimethylammonium (ODTMA) bromide ( $\geq 97 \%)$, molecular weight $(\mathrm{MW})=392.5, \quad \mathrm{CuSO}_{4} \cdot 5 \mathrm{H}_{2} \mathrm{O} \quad(\geq 97 \%), \quad \mathrm{MW}=$ 249.7, and thiabendazole [2-(thiazol-4-yl) benzimidazole] (TBZ), $\mathrm{MW}=201.3, \mathrm{pK}_{\mathrm{a}}$ values $=2.5,4.7$ and 12.0 , and solubility in water at $20 \pm 0.5^{\circ} \mathrm{C}=0.16 \mathrm{~g} / \mathrm{L}$ at $\mathrm{pH} 4$ and $0.03 \mathrm{~g} / \mathrm{L}$ at pH 7-10 [26], were supplied by Fluka (Buchs, Switzerland). All chemicals were of analytical grade and used without further purification.

The organo-Mt sample (OMt) with ODTMA exchanged at 55\% CEC was obtained and characterized previously [12].

The Acremonium-clay biocomposite was generated by growing Acremonium sp. (Acre sp.) biomass on Mt clay as indicated in former study [22]: the biomass was grown axenically in aerobic batch cultures, on the Mt clay $1 \%(\mathrm{w} / \mathrm{v})$ in the presence of the culture medium P5. The biocomposite (denoted BMt) was isolated by centrifugation (20 min, 15,000 rpm), water rinsed and dried at $80^{\circ} \mathrm{C}$ 
prior to being used. A detailed characterization of the BMt was previously published in Olivelli et al. [22].

To attain $\mathrm{Cu}^{2+}$-loaded $\mathrm{Mt}$ or OMt samples (labelled as $\mathrm{Mt}-\mathrm{Cu}$ and $\mathrm{OMt}-\mathrm{Cu}), 10 \mathrm{~g}$ of each sample was initially dispersed in $500 \mathrm{~mL}$ of water, and a $\mathrm{Cu}^{2+}\left(\mathrm{CuSO}_{4} \cdot 5 \mathrm{H}_{2} \mathrm{O}\right)$ amount equivalent to 1.5 CEC was slowly added. The suspensions were stirred overnight at $25^{\circ} \mathrm{C}$. The $\mathrm{pH}$ values of the suspensions were 4.8 and 4.7 for $\mathrm{Mt}$ and OMt, respectively. The products were rinsed three times with deionized water, dried at $80^{\circ} \mathrm{C}$, and ground in an agate mortar. To attain the $\mathrm{Cu}^{2+}$-loaded BMt sample (labelled as BMt-Cu), BMt sample was added to a $200 \mathrm{mg} / \mathrm{L} \mathrm{Cu}^{2+}$ solution (solid/solution ratio $=1 \mathrm{~g} / \mathrm{L}$ ) and stirred overnight. The BMt-Cu sample was recovered by centrifugation. $\mathrm{Cu}^{2+}$ contents were $0.309,0.124$ and $0.243 \mathrm{mmol} / \mathrm{g}$ for $\mathrm{Mt}-\mathrm{Cu}, \mathrm{OMt}-\mathrm{Cu}$ and $\mathrm{BMt}-\mathrm{Cu}$, respectively, determined by $\mathrm{HNO}_{3}$ digestion and atomic absorption spectroscopy (additional details in the Section 3.2).

The TBZ- $\mathrm{Cu}^{2+}$ complex was obtained following the methodology in [16]: TBZ (1.22 g, $6 \mathrm{mmol})$ was dissolved in $20 \mathrm{~mL}$ of ethanol, and $\mathrm{CuSO}_{4} \cdot 5 \mathrm{H}_{2} \mathrm{O}(0.75 \mathrm{~g}, 3 \mathrm{mmol})$ dissolved in $5 \mathrm{~mL}$ of water was added. After 3 days of stirring $(150 \mathrm{rpm})$ at room temperature, a green powder precipitated and was separated by filtration and dried at $60^{\circ} \mathrm{C}$ for $24 \mathrm{~h}$.

\subsection{TBZ adsorption studies}

A weighed amount of the pure fungicide was dissolved in deionized water in order to prepare a $25 \mathrm{mg} / \mathrm{L}$ solution, and further concentrations were obtained by dilution in deionized water.

The adsorption experiments were carried out with a contact time of $8 \mathrm{~h}$, at $20^{\circ} \mathrm{C}$, under stirring $(150 \mathrm{rpm})$ and without $\mathrm{pH}$ adjustment in order to evidence acid-base reactions.

Batch adsorption experiments were performed with a solid/ solution ratio of $1 \mathrm{~g} / \mathrm{L}$, using a TBZ concentration range from 0.5 to $25 \mathrm{mg} / \mathrm{L}$. After the equilibration time, the suspensions were centrifuged at $14,000 \mathrm{rpm}$ for $15 \mathrm{~min}$ to separate the reaction products. The solid phases corresponding to the highest initial concentration of TBZ studied $(25 \mathrm{mg} / \mathrm{L})$ were rinsed with distilled water, airdried, and stored for further analysis. The concentration of TBZ in the supernatants was analysed by high performance liquid chromatography (HPLC) coupled with UV-visible $(\lambda=298 \mathrm{~nm})$ and fluorescence $\left(\lambda_{\mathrm{ex}}=300 \mathrm{~nm}\right.$ and $\left.\lambda_{\mathrm{em}}=350 \mathrm{~nm}\right)$ detection using a Shimadzu HPLC C18 column $(4.6 \mathrm{~mm} \times 250 \mathrm{~mm}, 4.6 \mu \mathrm{m})$. The mobile phase was a 70/30 methanol/water mixture flowing at $0.9 \mathrm{~mL} / \mathrm{min}$. The injected volume was $10 \mu \mathrm{L}$. The linear ranges of TBZ concentrations were within $0.5-25 \mathrm{mg} / \mathrm{L}\left(R^{2}=0.999\right)$ and within $0.1-5 \mathrm{mg} / \mathrm{L}\left(R^{2}=0.999\right)$ using UV and fluorescence detection, respectively. The TBZ adsorbed amount, $q$, (mg TBZ/g adsorbent) was determined as the difference between the initial TBZ concentration $\left(C_{i}\right)$ and that at equilibrium $\left(C_{e}\right)$.

With the aim of comparing adsorbent-adsorbate affinities and the adsorbent performance, a mathematical model that could adequately fit the experimental data of the isotherms of all samples was sought. Langmuir (Eq. (1)), Freundlich (Eq. (2)) and Langmuir-Freundlich (LF, Eq. (3)) equations were tested.

$q=\frac{q_{\max , L} K_{L} C_{e}}{1+\left(C_{e} K_{L}\right)}$

$q=k_{F} C_{e}^{n}$

$q=\frac{q_{\max }\left(K_{s} C_{e}\right)^{n}}{1+\left(C_{e} K_{s}\right)^{n}}$

Langmuir isotherm model (Eq. (1)) assumes a monolayer adsorption on a surface with a finite number of identical sites, where all sites are energetically equivalent and without any inter- action between adsorbed molecules. In Eq. (1), $q_{\max , L}$ is the maximum amount adsorbed within a monolayer $(\mathrm{mg} / \mathrm{g})$, and $K_{L}(\mathrm{~L} /$ $\mathrm{mg}$ ) is the Langmuir dissociation constant, which is related to the adsorption energy.

Freundlich expression (Eq. (2)) is an empirical equation based on the adsorption on a heterogeneous surface consisting of sites with different exponential distributions and energies. In Eq. (2), $k_{F}(\mathrm{~L} / \mathrm{mg}$ ) indicates adsorption capacity, and $n$ (dimensionless) indicates the degree of surface heterogeneity.

Langmuir-Freundlich (LF) model (Eq. (3)) combines both Freundlich and Langmuir isotherms in a three-parameter equation. It was proposed to circumvent the impossibility to approach an adsorption maximum at high concentrations encountered in the Freundlich model [27]. In Eq. (3) $q_{\max }$ is the maximum adsorption capacity of the adsorbent $(\mathrm{mg} / \mathrm{g}), K_{S}(\mathrm{~L} / \mathrm{mg})$ is the affinity constant for adsorption, and $n$ is the Freundlich parameter that characterizes the material heterogeneity. The LF isotherm is reduced to the Langmuir form for $n=1$, and a homogeneous surface is considered. The greater the difference from this value, the greater the clay surface heterogeneity [28].

To study the effect of the adsorbent dose on TBZ adsorption, the removal efficiency (E,\%) was determined for a TBZ initial concentration $=25 \mathrm{mg} / \mathrm{L}$ and three different solid/solution ratios $(1,0.5$ and $0.1 \mathrm{~g} / \mathrm{L}$ ). Adsorption experiments were carried out following previous indications, and the removal efficiency was calculated by Eq. (4):

$E=\frac{C_{i}-C_{e}}{C_{i}} \times 100 \%$

where: $C_{i}$ and $C_{e}$ are the initial and equilibrium TBZ concentrations in the solution phase, respectively. All experiments were carried out in triplicate, and the relative standard deviation was calculated. An adsorbate blank (without pesticide spiking) and a solution blank (without clay) were carried out simultaneously for all treatments as a control to monitor interference.

\subsection{Samples characterization}

Adsorbents and TBZ adsorbed products $\left(C_{i}=25 \mathrm{mg} / \mathrm{L}\right.$, solid/ solution ratio $=1 \mathrm{~g} / \mathrm{L}$ and labelled by adding $-\mathrm{TBZ}$ to the name of the adsorbent) were analysed using different techniques.

XRD patterns (001 peak) were collected on random powder samples from $2^{\circ}$ to $15^{\circ}(2 \theta)$ with a counting time of $10 \mathrm{~s} / \mathrm{step}$ and $0.02^{\circ}(2 \theta)$ step size, using a Philips PW 1710 diffractometer, operated at $40 \mathrm{kV}$ and $30 \mathrm{~mA}$ with $\mathrm{CuK}_{\alpha}$ radiation $(\lambda=0.154 \mathrm{~nm})$.

High-resolution ${ }^{13} \mathrm{C}$ solid-state spectra for the different compounds were recorded using the ramp ${ }^{1} \mathrm{H}_{-}{ }^{13} \mathrm{C}$ CP-MAS sequence (cross-polarization and magic angle spinning) with proton decoupling during acquisition. All the ss-NMR experiments were performed at room temperature in a Bruker Avance II-300 spectrometer equipped with a 4-mm MAS probe. The operating frequency for protons and carbons was 300.13 and $75.46 \mathrm{MHz}$, respectively. Glycine was used as an external reference for the ${ }^{13} \mathrm{C}$ spectra and to set the Hartmann-Hahn matching condition in the cross-polarization experiments in ${ }^{13} \mathrm{C}$ spectra. The recycling time was $4 \mathrm{~s}$. The contact time during CP was $1500 \mu \mathrm{s}$ for the ${ }^{13} \mathrm{C}$ spectra. The SPINAL64 sequence (small phase incremental alternation with 64 steps) was used for heteronuclear decoupling during acquisition with a proton field $\mathrm{H}_{1 \mathrm{H}}$ satisfying $\omega_{1 \mathrm{H}} / 2 \pi=$ $\gamma_{\mathrm{H}} \mathrm{H}_{1 \mathrm{H}}=62 \mathrm{kHz}$ [29]. The spinning rate for all the samples was $10 \mathrm{kHz}$.

EPR measurements of the $\mathrm{Cu}^{2+}$-loaded samples were performed at X-band on a Bruker EMX Plus Spectrometer at $20^{\circ} \mathrm{C}$. The spectrometer settings were: microwave frequency $9.87 \mathrm{GHz}$; modulation field $100 \mathrm{kHz}$; modulation amplitude $4 \mathrm{G}$; microwave power 
$0.2 \mathrm{~mW}$, and 2040 points of resolution. The number of scans in all the experiments was 100 .

Thermogravimetric (TG) experiments were conducted using a NETZSCH STA 409 PC/PG with alumina as a reference. Samples of $20 \mathrm{mg}$ were placed in Pt crucibles and heated from 30 to $1000{ }^{\circ} \mathrm{C}$ at a rate of $10^{\circ} \mathrm{C} / \mathrm{min}$ in nitrogen/air atmosphere. The differential thermogravimetric (DTg) curves were directly derived from the corresponding TG curves.

To determine the $\mathrm{Cu}^{2+}$ content in $\mathrm{Cu}^{2+}$-loaded samples (before and after TBZ adsorption), $1 \mathrm{~g}$ of solids was digested in $20 \mathrm{~mL}$ of concentrated $\mathrm{HNO}_{3}$ at $60{ }^{\circ} \mathrm{C}$ until evaporation. This procedure was repeated twice. The obtained solids were suspended in a diluted $\mathrm{HNO}_{3}: \mathrm{H}_{2} \mathrm{O}$ solution (1:1). The suspension was filtered and the supernatant recovered. $\mathrm{Cu}^{2+}$ concentration in the supernatant was determined by atomic absorption spectroscopy using SensAA dual GBC Sci. equipment.

\subsection{Leaching experiments}

In order to determine the mobility of both $\mathrm{TBZ}$ and $\mathrm{Cu}^{2+}$ from the waste solids obtained after adsorption, US Environmental Protection Agency (EPA) Test Method 1312 was followed [30].

A suspension containing $\mathrm{Cu}^{2+}$ and/or TBZ-loaded samples and a diluted $\mathrm{H}_{2} \mathrm{SO}_{4} / \mathrm{HNO}_{3}(60 / 40 \mathrm{wt} \%$ mixture $)$ solution at $\mathrm{pH}=4.2$ ( solid/solution ratio $=1 / 20$ ) was shaken overnight at $25^{\circ} \mathrm{C}$ and centrifuged $(14,000 \mathrm{rpm})$. Leached $\mathrm{Cu}^{2+}$ and TBZ were quantified using atomic absorption and HPLC techniques, respectively. This procedure was carried out in duplicate, and the main values with their relative standard deviation were obtained.

\section{Results and discussion}

\subsection{Adsorption isotherms}

The $\mathrm{pH}$ of the isotherms was measured before and after the equilibration time in order to identify the presence of acid-base reactions. The $\mathrm{pH}$ variation during the equilibration time suggested that an acid-base reaction took place, while those where the $\mathrm{pH}$ remained constant indicated that in the adsorption process neither $\mathrm{H}^{+}$nor $\mathrm{OH}^{-}$were involved. The $\mathrm{pH}$ remained constant at $\mathrm{pH}=6.5$ for $\mathrm{Cu}^{2+}$-loaded samples, while it changed from 6.5 to $\mathrm{pH}=8.5$; 7.5 and 7.0 for Mt, OMt and BMt samples, respectively.

The mechanism proposed to explain the adsorption of TBZ onto raw montmorillonite is the cationic exchange between interlayer $\mathrm{Na}^{+}$and $\mathrm{TBZH}^{+}$, as was suggested in a previous work [13]:

$\equiv \mathrm{X}^{-} \mathrm{Na}^{+}+\mathrm{TBZ}+\mathrm{H}_{2} \mathrm{O} \rightarrow \equiv \mathrm{X}^{-}\left(\mathrm{TBZH}^{+}\right)+\mathrm{Na}^{+}+\mathrm{OH}^{-}$

where $\equiv \mathrm{X}^{-}$are the permanent charge sites. This mechanism was confirmed previously [31] by the pH data obtained in each point of the isotherms, which increased from 6.5 to 8.5 due to the increase of $\mathrm{OH}^{-}$concentration in the suspension. In the next paragraphs the mechanism of TBZ adsorption onto the other samples will be addressed. (see Fig. 1).

Langmuir and Freundlich models did not fit well with experimental data for all the samples (Table S1), contrary to that found for the LF model $\left(R^{2} \geqq 0.92\right)$ as is summarised in Table 1 . The good agreement with experimental data (Fig. 2 and Table 1) found by

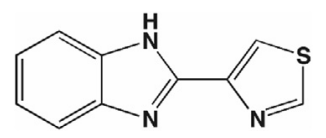

Fig. 1. Molecular structure of thiabendazole.
Table 1

Langmuir and Freundlich equation parameters for the adsorption of TBZ on indicated adsorbents.

\begin{tabular}{lllll}
\hline Sample & $\mathrm{R}^{2}$ & $q_{\max }(\mathrm{mg} / \mathrm{g})$ & $K_{s}(\mathrm{~L} / \mathrm{mg})$ & $n$ \\
\hline Mt & 0.920 & $14 \pm 2$ & $1.7 \pm 0.8$ & $1.2 \pm 0.7$ \\
Mt-Cu & 0.993 & $28 \pm 2$ & $8 \pm 1$ & $1.7 \pm 0.3$ \\
OMt & 0.989 & $14 \pm 2$ & $0.3 \pm 0.1$ & $0.8 \pm 0.1$ \\
OMt-Cu & 0.970 & $27 \pm 2$ & $13 \pm 2$ & $1.7 \pm 0.4$ \\
BMt & 0.989 & $23 \pm 1$ & $1.4 \pm 0.1$ & $1.9 \pm 0.3$ \\
BMt-Cu & 0.984 & $47 \pm 2$ & $32 \pm 8$ & $3.0 \pm 0.6$ \\
\hline
\end{tabular}

the LF model allowed the comparison of the performance and affinity towards TBZ of all the adsorbents.

Organic or biomass modification of Mt affected differently the TBZ adsorption parameters. For OMt with respect to Mt sample, $q_{\max }$ remained constant and $K_{s}$ decreased, pointing out that the clay surface coverage by ODTMA did not favour fungicide adsorption. A more pronounced effect of ODTMA on TBZ adsorption was noticed when $137 \%$ CEC loading of the surfactant was evaluated, reaching $q$ values 50\% lower than that obtained for Mt (Fig. S1) at TBZ equilibrium concentration $=14 \mathrm{mg} / \mathrm{L}$. These observations suggested that the generally proposed mechanism for the adsorption of organic compounds onto organo-montmorillonites - organophilic partitioning - [32] does not accurately describe the TBZ adsorption behaviour onto OMt sample. Instead, the mechanism that depicted the TBZ adsorption onto OMt sample; may be the electrostatic interaction between the cationic form of the fungicide $\left(\mathrm{TBZH}^{+}\right)$ and permanent charge sites that remained free. In OMt sample remain almost $45 \% \mathrm{CIC}$ of $\mathrm{Na}^{+}$that could be exchanged by $\mathrm{TBZH}^{+}$ in the inner surface, explaining the $\mathrm{pH}$ increase from 6.5 to 7.5 (Eq. (5)). Furthermore, the fact that $55 \%$ of $\mathrm{Na}^{+}$had been replaced by ODTMA ${ }^{+}$in OMt sample explains the decrease in TBZ adsorption in this sample compared to raw Mt.

For BMt samples, the biomass load in the Mt sample promoted a huge increase in TBZ adsorption, shown by both the highest $q$ (Fig. 2) and $q_{\max }$ (Table 1) values. Probably the presence of negatively charged sites on the fungus cell wall acted as novel electrostatic binding sites for the fungicide.

Even though the $q_{\max }$ values were a mathematical extrapolation, because the adsorption isotherm plateau was not achieved, for all $\mathrm{Cu}^{2+}$-loaded samples (Fig. 2) the good fit to the mathematical model $\left(R^{2}>0.97\right)$ allowed the comparison among these samples. The presence of $\mathrm{Cu}^{2+}$ in the structure of the adsorbents led to an increase of twice the $q_{\max }$ value (Table 1) compared to the respective adsorbents without $\mathrm{Cu}^{2+}$. Moreover, the increase in $K_{s}$ values (Table 1) with respect to samples without $\mathrm{Cu}^{2+}$ highlighted the presence of more favourable adsorption sites [24]. The behaviour of both parameters suggested that $\mathrm{Cu}^{2+}$ may be involved in the TBZ interaction on the solid surfaces and may act as a new site for TBZ adsorption. Grevy et al. (2002) reported that both in solution and in the solid state TBZ coordinated to metal ions through the imidazol and thiazol nitrogen atoms and stabilised bis- and tris-chelated coordination compounds [15]. Therefore, $\mathrm{Cu}^{2+}$ complexation with TBZ could explain the obtained isotherms. A similar behaviour was observed for cysteine adsorption onto homoionic $\left(\mathrm{Na}^{+}, \mathrm{Ca}^{2+}\right.$ and $\left.\mathrm{Cu}^{2+}\right)$ montmorillonites in [33]. The authors showed that the adsorption and desorption of the amino acid depended on the interlayer cation: Na- and Ca-rich montmorillonites adsorbed and retained small amounts of cysteine and did not show interlayer cation-cysteine complexes, whereas the amino acid was adsorbed in a higher amount and strongly retained in the interlayer by $\mathrm{Cu}$-rich montmorillonites [33].

Summing up results show that TBZ adsorption on $\mathrm{Mt}-\mathrm{Cu}$, OMt$\mathrm{Cu}$ and BMt-Cu samples, may have occurred trough the following mechanism: 


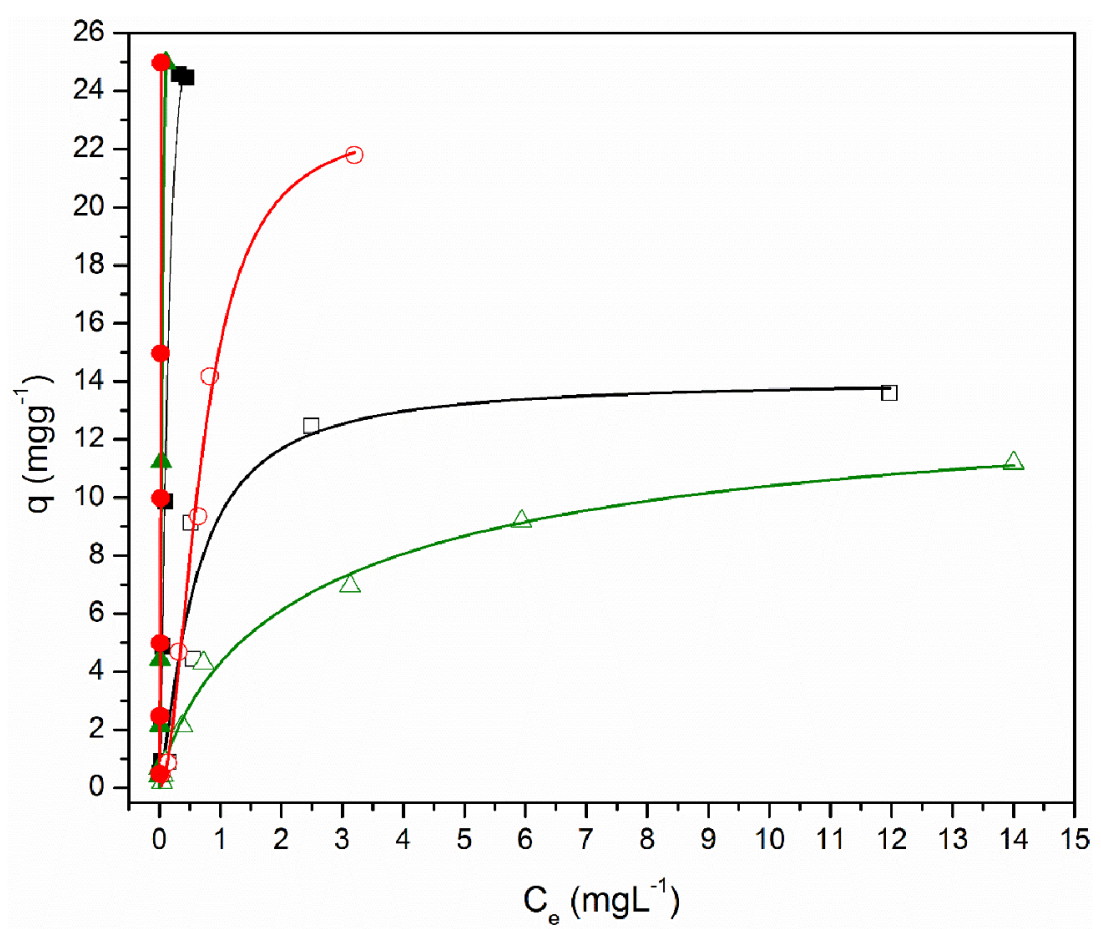

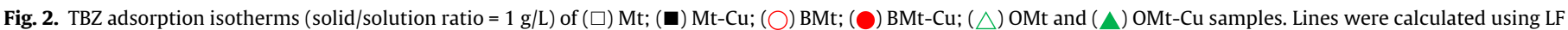
model.

$\equiv \mathrm{Cu}\left(\mathrm{H}_{2} \mathrm{O}\right)_{6}+n \mathrm{TBZ} \leftrightarrow \equiv \mathrm{Cu}\left(\mathrm{H}_{2} \mathrm{O}\right)_{6-2 n} \mathrm{TBZ}_{n}+2 n \mathrm{H}_{2} \mathrm{O}$

where $\equiv$ are surface sites for $\mathrm{Cu}^{2+}$. The displacement of two water molecules from the $\mathrm{Cu}^{2+}$ hydration sphere per thiabendazole molecule (since it is a bidentate ligand) is proposed. The ligand exchange reaction proposed by Eq. (6) is in agreement with $\mathrm{pH}$ constancy obtained in thiabendazole adsorption isotherms when $\mathrm{Cu}^{2+}$-loaded samples were used.

The fact that $n$ increased when $\mathrm{Cu}^{2+}$ was incorporated in the adsorbent structure (Table 1) was related to the development of surface heterogeneity, which indicated the existence of energetically different adsorption sites [28]. It is important to notice the presence of inner and edge sites in Mt and different functional groups in OMt and BMt where $\mathrm{Cu}^{2+}$ could be loaded, which reveals the chemical complexity of the surface adsorbents. The surface sites involved in the adsorption of both $\mathrm{Cu}^{2+}$ and TBZ will be deeply discussed in the Section 3.2.

The low solubility of TBZ in water limited upper limit of $C_{i}$ to be used in adsorption isotherms ( $25 \mathrm{mg} / \mathrm{L}$ ) and as a consequence, the isotherm plateaux were not attained for any $\mathrm{Cu}^{2+}$-loaded samples. In order to obtain more information on the yield of solids, the doses of all adsorbents were decreased, and the TBZ removal efficiency was determined. The TBZ adsorption efficiency, compared to that for the raw clay, in all tested solid/solution ratios (Fig. 3), showed no improvement for OMt, while the presence of biomass in BMt led to an enhancement of efficiency of around 60,25 and $10 \%$ for solid/solution ratios of $1,0.5$ and $0.1 \mathrm{~g} / \mathrm{L}$, respectively. Concerning $\mathrm{Cu}^{2+}$-loaded samples, the TBZ removal efficiency remained better than that of the respective samples without the metal cation, and attained a TBZ removal efficiency $>95 \%$ for solid/solution ratio $=1 \mathrm{~g} / \mathrm{L}$, regardless of the adsorbent (Fig. 3). Although the adsorbent dose was halved (from 1 to $0.5 \mathrm{~g} / \mathrm{L}$ ), this efficiency remained for the BMt-Cu and Mt-Cu samples, while it dropped to $68 \%$ for the OMt-Cu sample, in agreement with its lower metal content (as indicated in Table 3 ) than that of the previous samples. A further decrease of the solid/solution ratio to $0.1 \mathrm{~g} / \mathrm{L}$ promoted a

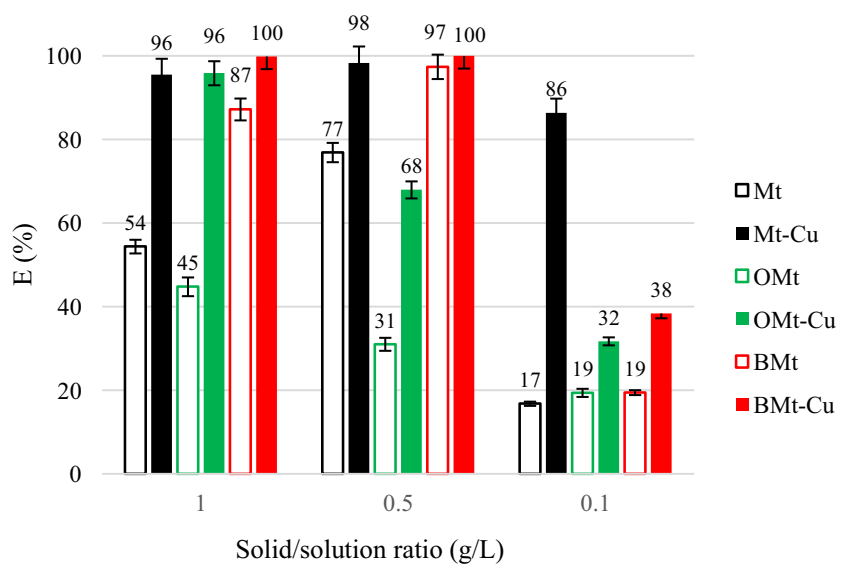

Fig. 3. Removal efficiency expressed as a percentage of a TBZ initial concentration $=25 \mathrm{mg} / \mathrm{L}$ using different adsorbent doses.

decrease in efficiency to $<40 \%$ for both BMt-Cu and OMt-Cu samples, while $86 \%$ of the initial TBZ was eliminated by Mt-Cu sample. These results were again in agreement with the higher $\mathrm{Cu}^{2+}$ loading of $\mathrm{Mt}-\mathrm{Cu}$ than that of the BMt-Cu and OMt-Cu samples (Table 3). Summing up, the results showed that the $\mathrm{Cu}^{2+}$ loading amount was important in TBZ retention. Nonetheless, as will be discussed in the next sections, not only the quantity but also the accessibility of $\mathrm{Cu}^{2+}$ to interact with the fungicide would define the adsorption capacity and mechanisms involved.

\subsection{Sample characterization}

\subsection{1. $X R D$}

The shift of the 001 peak gave information about the incorporation of surfactant, TBZ, metal or fungi in the Mt interlayer space (Fig. 4A, B and C, respectively) and allowed the identification of 
Table 3

Digestion and leaching results.

\begin{tabular}{|c|c|c|c|c|}
\hline Sample & $\mathrm{Cu}^{2+}$ content $(\mathrm{mmol} / \mathrm{g})$ & TBZ content $(\mathrm{mmol} / \mathrm{g})$ & Leached $\mathrm{Cu}^{2+}(\%)$ & Leached TBZ (\%) \\
\hline $\mathrm{Mt}-\mathrm{Cu}$ & $0.31 \pm 0.05$ & n.a. & $24 \pm 2$ & n.a. \\
\hline Mt-TBZ & n.a. & $0.059 \pm 0.001$ & n.a. & $8.3 \pm 0.2$ \\
\hline Mt-Cu-TBZ & $0.28 \pm 0.04$ & $0.12 \pm 0.05$ & $0.9 \pm 0.1$ & $0.003^{*}$ \\
\hline $\mathrm{OMt}-\mathrm{Cu}$ & $0.12 \pm 0.03$ & n.a. & $9.7 \pm 0.5$ & n.a. \\
\hline OMt-TBZ & n.a. & $0.044 \pm 0.005$ & n.a. & $0.06^{*}$ \\
\hline OMt-Cu-TBZ & $0.11 \pm 0.02$ & $0.13 \pm 0.02$ & $2.4 \pm 0.1$ & $0.005^{*}$ \\
\hline BMt-Cu & $0.24 \pm 0.04$ & n.a. & $9.3 \pm 0.2$ & n.a. \\
\hline BMt-TBZ & n.a. & $0.049 \pm 0.002$ & n.a. & $0.009^{*}$ \\
\hline BMt-Cu-TBZ & $0.22 \pm 0.03$ & $0.13 \pm 0.04$ & $4.5 \pm 0.1$ & $0.004^{*}$ \\
\hline
\end{tabular}

n.a. not applicable.

Data below the quantification limit.
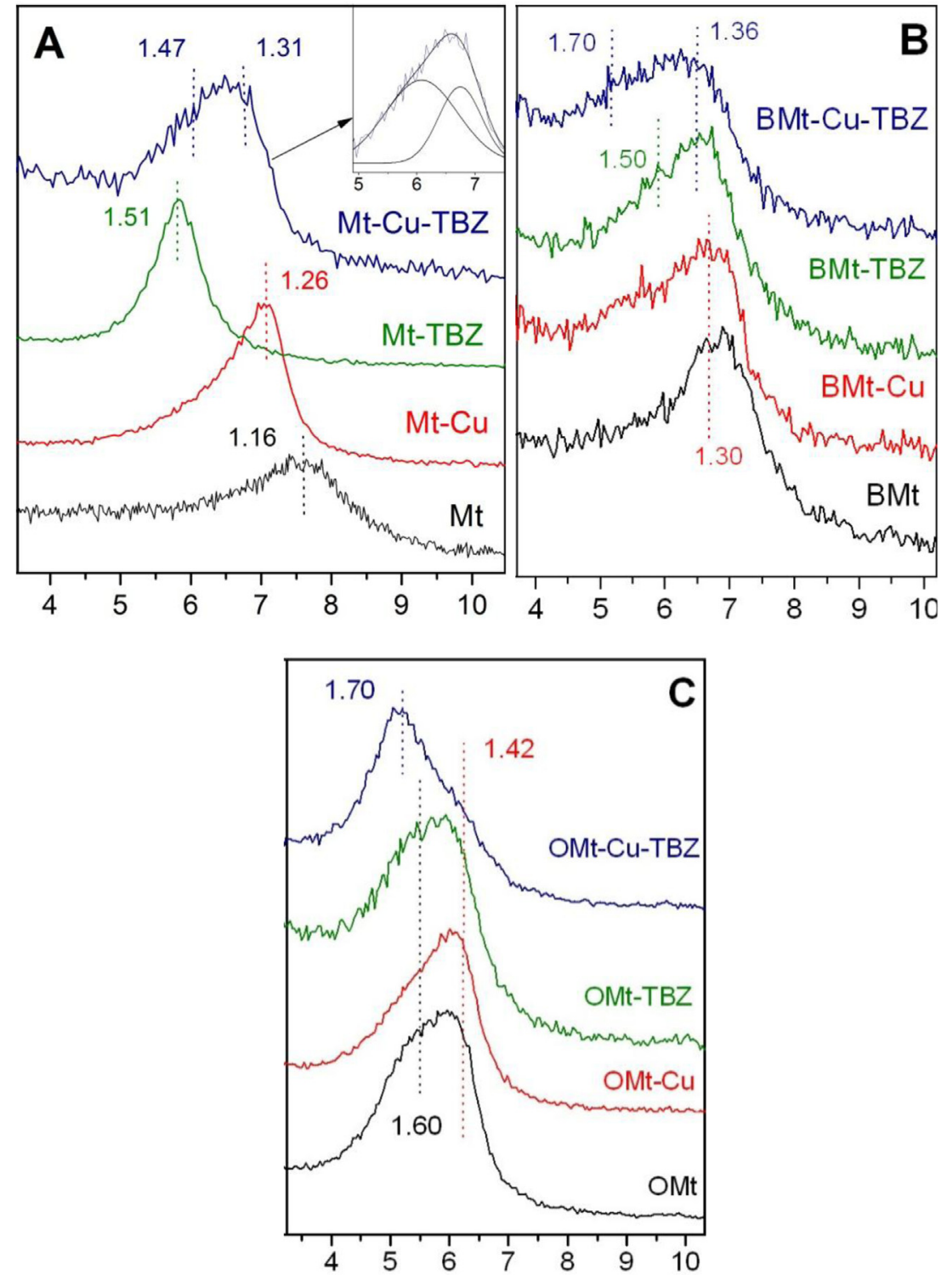

Fig. 4. XRD patterns (A) Mt, (B) BMt and (C) OMt sample series.

the sites involved in the interaction of the different species with the clay.

The incorporation of $\mathrm{Cu}^{2+}$ in the Mt interlayer shifted the 001 peak from 1.16 to $1.26 \mathrm{~nm}$ (Fig. 4A). Taking into account the $\mathrm{pH}=4.8$ used in the synthesis of $\mathrm{Mt}-\mathrm{Cu}$, it was expected that the permanent charge sites of Mt would be preferred for the adsorp- tion of $\mathrm{Cu}^{2+}[18]$. Therefore, the peak was assigned to the presence of hexa-aqueous complexes $\left[\mathrm{Cu}\left(\mathrm{H}_{2} \mathrm{O}\right)_{6}\right]^{2+}$ in the interlayer sites [34,35].

TBZ adsorption, whether onto Mt or Mt-Cu samples, shifted the 001 peak to lower theta values indicative of its interlayer entrance (Fig. 4A). For TBZ adsorbed on Mt sample, a 001 value of $1.51 \mathrm{~nm}$ 
was attained and assigned to a planar position of the fungicide between layers [13,14]. From the difference between the 001 value of Mt-TBZ sample $(1.51 \mathrm{~nm}$, Fig 4) and that of dehydrated Mt $(0.97 \mathrm{~nm})$, and taking into account TBZ molecular dimensions (length, $1.15 \mathrm{~nm}$; height, $0.71 \mathrm{~nm}$; thickness, $0.34 \mathrm{~nm}$; [13]) it is suggested that TBZ lies in the interlayer space parallel to the siloxane layers. The arrangement of $\mathrm{TBZH}^{+}$and neutral $\mathrm{TBZ}$ in $\mathrm{Na}-$ montmorillonite was also identified in a former study by molecular modelling [31].

For the $\mathrm{Mt}-\mathrm{Cu}$ sample, the subsequent adsorption of TBZ widened the reflection peak whose mathematical deconvolution suggested the presence of two 001 peaks (Fig. 4A).

The first one, centred at $1.47 \mathrm{~nm}$ (Fig. 4A), was attributed to $\mathrm{TBZ}_{-} \mathrm{Cu}^{2+}$ complex formation with displacement of some water molecules from the $\mathrm{Cu}^{2+}$ hydration sphere (Eq. (6)), and the consequent $0.04 \mathrm{~nm}$ interlayer contraction for $\mathrm{Mt}-\mathrm{Cu}-\mathrm{TBZ}$ with respect to Mt-TBZ. Similar TBZ-metal complexes ( $\mathrm{TBZ}-\mathrm{Ni}^{2+}$ and $\mathrm{TBZ}-\mathrm{Co}^{2+}$ ), confined in the interlayer space of Mt, were reported [13], with their interlayer arrangements being parallel to the layers.

The second 001 peak centred at $1.31 \mathrm{~nm}$ (Fig. 4A) was assigned to $\left[\mathrm{Cu}\left(\mathrm{H}_{2} \mathrm{O}\right)_{6}\right]^{2+}$ remaining in the basal positions. It is important to note that the molar ratio $\mathrm{Cu}^{2+} / \mathrm{TBZ}$ in Mt-Cu-TBZ sample was 2.57 $\left(0.309 \mathrm{mmol}\left[\mathrm{Cu}^{2+}\right] / 0.124 \mathrm{mmol}\right.$ [TBZ] per gram of sample). This value indicated that if all the TBZ molecules were in the interlayer space as TBZ- $\mathrm{Cu}^{2+}$ complexes, two-thirds of $\mathrm{Cu}^{2+}$ would still remain as aqueous complexes in the interlayer, and both 001 values would be present.

XRD patterns of BMt and OMt samples (Fig. 4B and C, respectively) were analysed in previous work $[12,24]$. Particularly, in BMt sample the fungi were bonded to the aluminosilicate edge framework, and a broad peak centred at $1.30 \mathrm{~nm}$ was assigned to the compensation between the interlayer shrinkage and expansion (originated by the ionic strength and exchange of some hydrated cations of the culture medium, respectively) during biomass growth. In OMt sample, the deconvolution of its wide 001 peak (Fig. 4C) indicated two interlayer distances, originated from the different arrangements of the alkyl chain of ODTMA, at 1.43 (lateral monolayer) and $1.60 \mathrm{~nm}$ (lateral bilayer) (Fig. S2). The $\mathrm{Cu}^{2+}$ loading in both samples (OMt-Cu and BMt-Cu) did not promote further shifts of the 001 peak (Fig. 4B and C, respectively). This could be due to the fact that in both samples the interlayer was separated enough to allow some metal cation entrance.

TBZ adsorption onto BMt sample (Fig. 4B) widened the 001 peak, whose mathematical deconvolution (Fig. S2) indicated two main peak values centred at $1.36 \mathrm{~nm}$, assigned to an interlayer free of TBZ, and at $1.5 \mathrm{~nm}$ attributed to TBZ planar arrangement in the interlayer. No shifts in the 001 peak were observed in OMt-TBZ with respect to OMt sample. As previously occurred for imazalil adsorption onto ODTMA-Mt clays [12], in OMt-TBZ sample the surfactant acted as a pillar holding an open interlayer, allowing the fungicide entrance without further enlargement.

The incorporation of $\mathrm{Cu}^{2+}$ in the interlayer space in the modified Mt samples (BMt-Cu and OMt-Cu) and its availability to interact with TBZ was confirmed by changes in the XRD patterns. In BMtCu-TBZ and OMt-Cu-TBZ samples (Fig. 4B and C, respectively) a new component at $1.70 \mathrm{~nm}$ was found (Fig. S2) and attributed to $\mathrm{TBZ}_{-} \mathrm{Cu}^{2+}$ complex formation. The different $\mathrm{d} 001$ value found for these samples $(1.70 \mathrm{~nm})$ with respect to $\mathrm{Mt}-\mathrm{Cu}-\mathrm{TBZ}$ sample $(1.47 \mathrm{~nm})$ could be assigned to a different chemical environment in the interlayer space of BMt-Cu and OMt-Cu than in $\mathrm{Mt}-\mathrm{Cu}$ samples, which promoted a different geometry or sphere of coordination of the respective complexes formed.

\subsubsection{Solid-state nuclear magnetic resonance and electron paramagnetic resonance studies}

Although TBZ and $\mathrm{Cu}^{2+}$ entered the interlayer space in BMt sample, it is known that fungi present some specific bonding sites for the uptake of the metal cation. In order to characterize the modification of Mt with Acre sp., ${ }^{13} \mathrm{C}$ CP-MAS spectra of BMt were recorded, and the results are shown in Fig. 5. The BMt sample exhibited carbon resonance signals corresponding to polysaccharides commonly found in the cellular wall of fungi (Fig. 5A), similar to those found in chitosan, chitin and related compounds [36]. The absence of signals at $90 \mathrm{ppm}$ indicated that the contribution of cellulose related to the polysaccharide content in the sample was low [37]. Also, some other signals at a ${ }^{13} \mathrm{C}$ chemical shift around $40-$ $10 \mathrm{ppm}$ could indicate the presence of some amino acids corresponding to oligopeptides bearing aliphatic residues. The signal at $172.8 \mathrm{ppm}$ was assigned to the carbonyl carbon of the acetylated amino groups present in the polysaccharide ( $\mathrm{N}$-acetylglucosaminelike residues) together with the carbonyl group of carboxylic acid of amino acids or amide-type carbon of oligopeptides present in the BMt sample. After the uptake of $\mathrm{Cu}^{2+}$ (Fig. 5B), the intensity of the ${ }^{13} \mathrm{C}$ NMR lines was affected since the paramagnetic ions enhanced the relaxation of the different carbons and protons that were next to the $\mathrm{Cu}^{2+}$ sites, affecting the visualization of the NMR signal [38]. The aliphatic segment at $40-10 \mathrm{ppm}$ together with the carbonyl carbon at 172.8 ppm were particularly affected, allowing the prediction of a selectivity for the uptake of $\mathrm{Cu}^{2+}$ related to the amide carbon present in the $\mathrm{N}$-acetylglucosamine residues and/or the oligopeptides present in BMt sample [39]. For instance, the intensity of $C_{1}$ at $110 \mathrm{ppm}$ was practically not
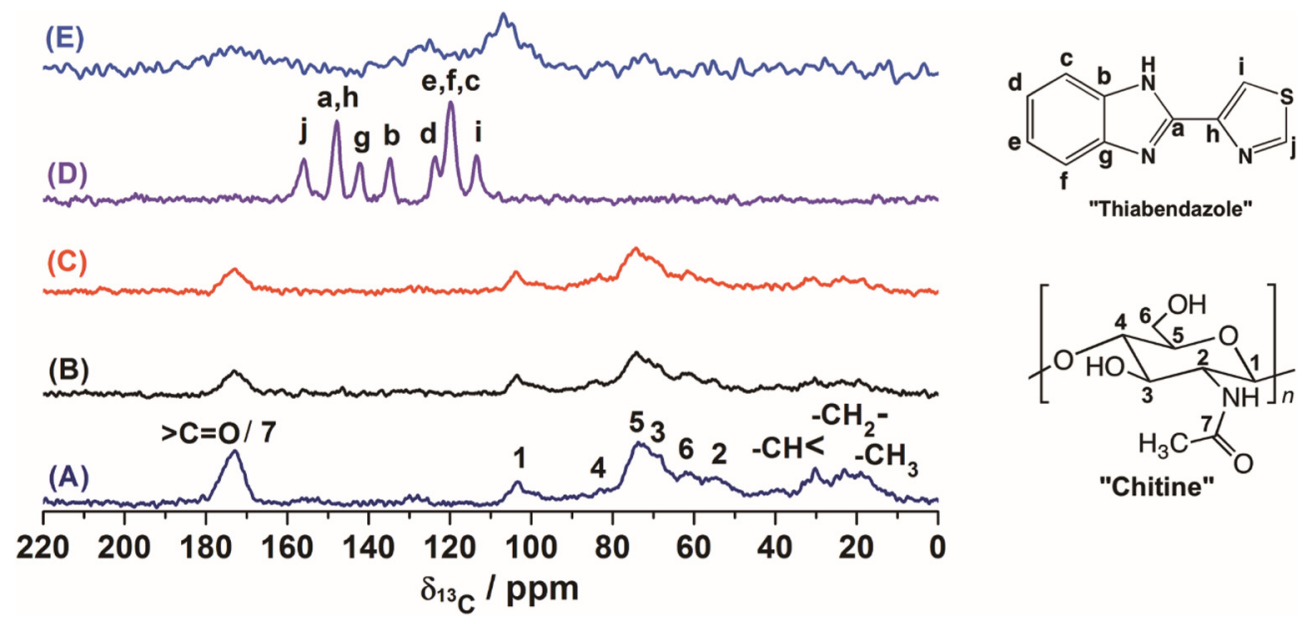

Fig. 5. ${ }^{13} \mathrm{C}$ CP-MAS spectra for (A) BMt, (B) BMt-Cu, (C) BMt-Cu-TBZ, (D) pure TBZ, and (E) TBZ-Cu ${ }^{2+}$ complex. 
affected by the presence of $\mathrm{Cu}^{2+}$, indicating that part of the polysaccharide did not participate in the uptake of the metal ion.

Even though the NMR signals were affected due to the proximity to the $\mathrm{Cu}^{2+}$ centre, the exact sphere of coordination could not be determined from this experiment. The same NMR results were observed when BMt-Cu was treated with TBZ (Fig. 5C); however, the resonance signals corresponding to TBZ could not be observed in the range of $110-160 \mathrm{ppm}$ where the signals for the pure TBZ were present (Fig. 5D). The absence of NMR signals for the TBZ molecules in BMt-Cu-TBZ sample was associated with the enhancement in the relaxation of carbons induced by $\mathrm{Cu}^{2+}$, since all the TBZ molecules were bonded to the paramagnetic sites. The TBZ-Cu ${ }^{2+}$ complex in Fig. 5E showed how the NMR signals in the pure TBZ were affected due to the coordination with copper. In addition, a broad signal at $\sim 175 \mathrm{ppm}$ was observed for some of the ${ }^{13} \mathrm{C}$ signals in TBZ- $\mathrm{Cu}^{2+}$ complex in comparison with pure TBZ, demonstrating that TBZ was a ligand for $\mathrm{Cu}^{2+}$. The unequivocal assignment in the ${ }^{13} \mathrm{C} \mathrm{CP}$-MAS spectrum of TBZ was done with the NQS experiment together with the solution ${ }^{13} \mathrm{C}$ NMR spectrum in DMSO- $d_{6}[15]$. Based on these results and previous XRD discussion, it was concluded that $\mathrm{Cu}^{2+}$ was located both at interlayer sites and bonded to amino acid or amide residues in the fungus cellular wall in BMt-Cu sample. The exact sphere of coordination of the metal cation in BMt-Cu could not be described from the experiments, but $\mathrm{TBZ}-\mathrm{Cu}^{2+}$ complex formation in BMt-Cu-TBZ sample was unambiguously confirmed.

The ${ }^{13} \mathrm{C}$ CP-MAS spectrum for the Mt modified with ODTMA (data not shown) did not originate NMR signals, even though the presence of ODTMA in the clay structure has been previously determined [12]. The absence of ${ }^{13} \mathrm{C}$ resonance signals in the OMt samples, even with a high number of scans, may be associated with an amorphous state of the hydrocarbon chain of ODTMA in the clay structure (which was consistent with different 001 peaks found by XRD analysis) together with a low density of adsorbed OMt in the sample (55\% CEC), preventing an adequate transfer of the polarization from ${ }^{1} \mathrm{H}$ to ${ }^{13} \mathrm{C}$ in the ${ }^{13} \mathrm{C}$ acquisition experiment in the solid state [40].

The X-band EPR spectra were recorded in order to gather information on the coordination of $\mathrm{Cu}^{2+}$ to the clay structure in the first instance, and then to follow the uptake of TBZ molecules involving the paramagnetic sites together with the generation of new $\mathrm{Cu}^{2+}$ complexes in the different clay samples. The EPR results are presented in Fig. 6. The $\mathrm{Cu}^{2+}$ adsorbed on the different samples showed two fine structure lines around g-values of 2.07 and 2.14 , together with a broad and unresolved hyperfine region at $\mathrm{g}=2.20-2.70$ with different intensity among the samples. The signal at $\mathrm{g}=2.12$ was associated with free hydrated $\mathrm{Cu}^{2+}$ ions or coordinated with hydroxyl groups and water molecules in the interlayer of the $\mathrm{Mt}$ structure in $\mathrm{Mt}-\mathrm{Cu}$ and $\mathrm{BMt}-\mathrm{Cu}$ samples $[22,41]$. As was stated above for BMt-Cu sample, some $\mathrm{Cu}^{2+}$ ions were coordinated to biomass functional groups, and some were in the interlayer positions coordinated with water.

Particularly, the OMt-Cu sample presented an EPR line similar to those in BMt-Cu and $\mathrm{Mt}-\mathrm{Cu}$;despite, the contribution at $\mathrm{g}$ $\sim 2.13$ could not be well resolved due to the presence of different sites for the paramagnetic ions taking into account that ODTMA intercalation in the Mt structure produced a heterogeneous environment for the hydrated $\mathrm{Cu}^{2+}$ sites with the concomitant EPR signal broader than in the other Cu-samples. The presence of ODTMA affected the sites available for $\mathrm{Cu}^{2+}$ in OMt sample. ODTMA was located at the permanent charge sites and some at the external surface of Mt [12]. The incorporation of ODTMA cations into the interlayer space (permanent charge sites) would not favour, from both kinetic and thermodynamic points of view, the subsequent uptake of $\mathrm{Cu}^{2+}$ in OMt sample. This explained the lower $\mathrm{Cu}^{2+}$ loading in OMt $(0.124 \mathrm{mmol} / \mathrm{g})$ in comparison with that for Mt sample $(0.309 \mathrm{mmol} / \mathrm{g})$. Furthermore, it was expected that some $\mathrm{Cu}^{2+}$ ions would be bonded to edge sites of OMt sample [6], although this fact could not be confirmed by the present techniques.

For BMt sample, biomass incorporation in the interlayer was limited (as was mentioned in the XRD Section) but also affected the amount of $\mathrm{Cu}^{2+}$ adsorbed $(0.243 \mathrm{mmol} / \mathrm{g})$, showing a similar EPR spectrum to that found for Mt-Cu sample. However, the slight difference in the EPR spectrum for BMt-Cu with respect to $\mathrm{Mt}-\mathrm{Cu}$ sample was attributed to the presence of $\mathrm{N}$-acetylglucosaminelike polymers in the BMt-Cu sample that participated involving the oxygen of the amide group [39] in the uptake of $\mathrm{Cu}^{2+}$, according to $s$-NMR results (Fig. 5). The other signal at $g=2.07$ was attributed to the specific adsorption of $\mathrm{Cu}^{2+}$ on the hexagonal cavities of Mt according to previous results reported in [22].
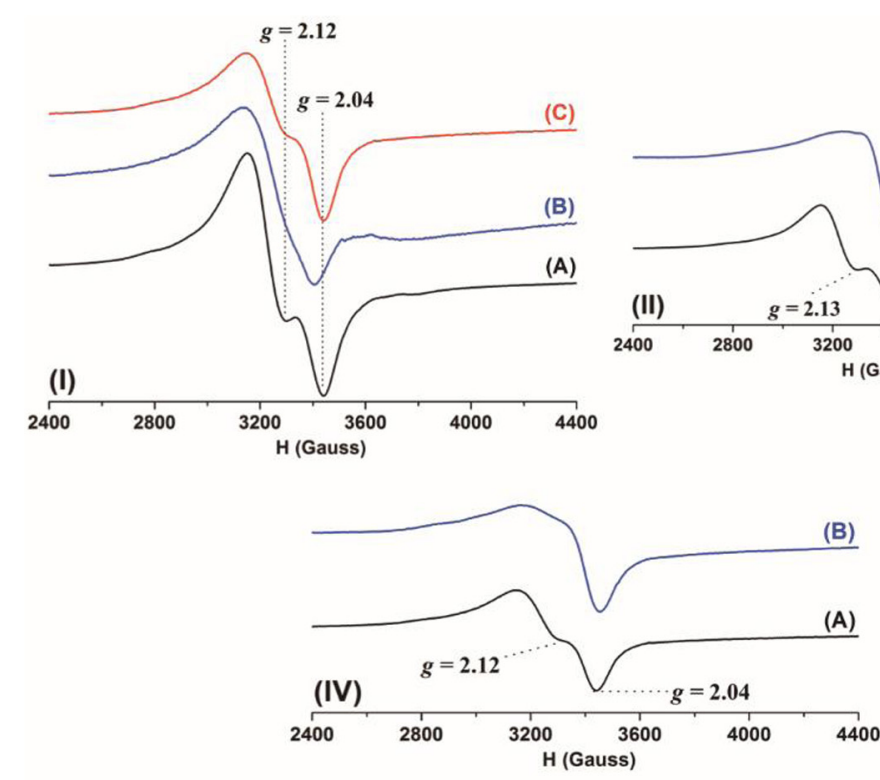
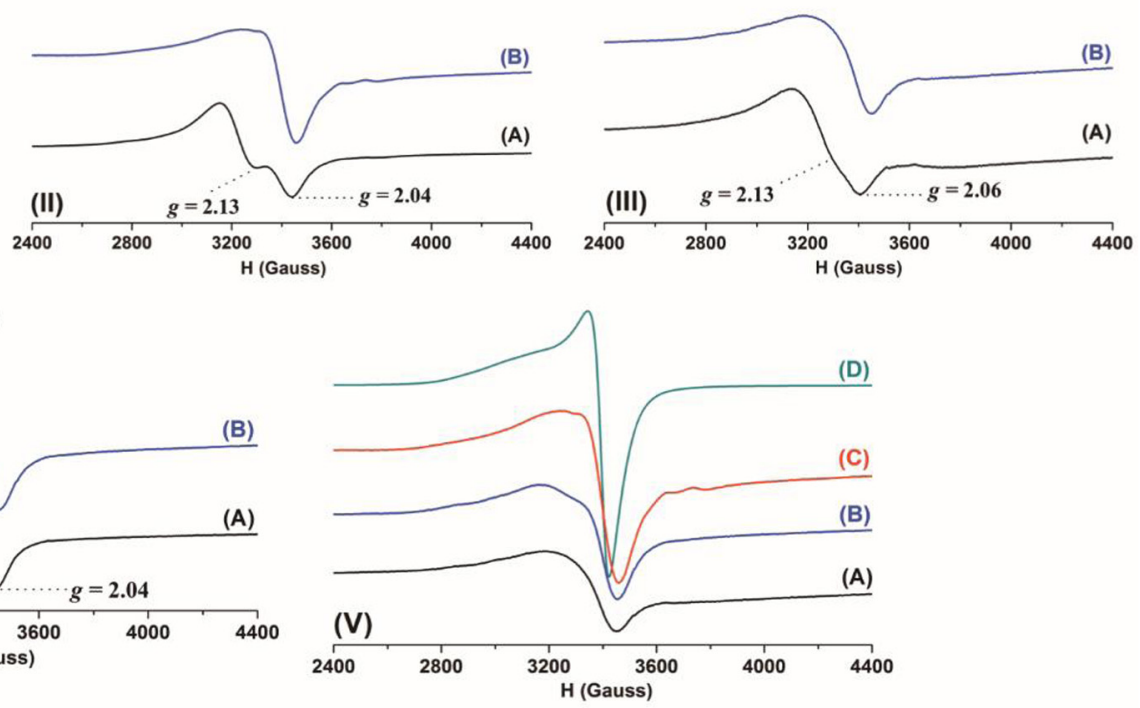

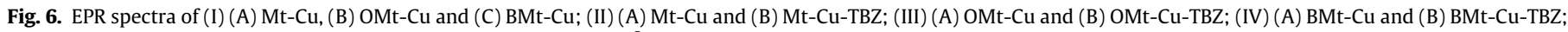
(V) (A) OMt-Cu-TBZ, (B) BMt-Cu-TBZ, (C) Mt-Cu-TBZ and (D) TBZ-Cu ${ }^{2+}$. 
When the TBZ molecules were adsorbed on the different materials, similar EPR changes were observed. In all the samples, the EPR spectra showed the TBZ- $\mathrm{Cu}^{2+}$ coordination since the hyperfine component was more significant than in the initial $\mathrm{Cu}^{2+}$-loaded samples. This indicated that TBZ exchanged water molecules as well as hydroxyl groups [42] from the sphere of the metal ion in agreement with the interlayer contraction observed in $\mathrm{Mt}-\mathrm{Cu}-$ TBZ with respect to Mt-TBZ - giving rise to new modes of coordination where the nitrogen atoms of TBZ played an important role in its inclusion in the samples. Specifically, the chelation through the imidazolic and thiazolic nitrogens of the TBZ molecules was inferred due to the shift to high field values of the EPR lines associated with the nitrogen effect that increased the $A_{\text {II }}$ values and reduced the $\mathrm{g}_{\text {II }}$ values in comparison with the oxygen surrounding the paramagnetic centre in the $\mathrm{Cu}^{2+}$-loaded samples before the addition of TBZ [38,42]. However, the high density of $\mathrm{Cu}^{2+}$ affected the resolution in the hyperfine region, making it impossible to obtain more information about the ligands of the $\mathrm{Cu}^{2+}$ centres. For that reason, a broad EPR signal was observed due to the proximity of the paramagnetic $\mathrm{Cu}^{2+}$ centres undergoing spin-orbit and exchange interactions, with a distance between the different $\mathrm{Cu}^{2+}$ sites that was usually less than 10-15 $\AA$ [43]. An example of this phenomenon is shown in the EPR spectrum of the synthesised TBZ- $\mathrm{Cu}^{2+}$ complex in Fig. 6.

Once again, BMt-Cu-TBZ was different from the rest of the TBZ$\mathrm{Cu}^{2+}$-loaded samples, taking into account that the shift of the EPR line of BMt-Cu-TBZ to high field values was not so evident (Fig. 6). This behaviour indicated that part of the $\mathrm{Cu}^{2+}$ that was retained in the biomass was not so available for the ligand exchange with TBZ, since the EPR line in BMt-Cu-TBZ had a tendency to lower $\mathrm{g}_{\mathrm{II}}$ values in comparison with OMt- and $\mathrm{Mt}-\mathrm{Cu}-$ TBZ samples. However, the $\mathrm{Cu}^{2+}$ retained in the interlayer space exchanged the local ligands (water) for TBZ, giving rise to more than one coordination mode together with some $\mathrm{Cu}-\mathrm{Cu}$ dipolar interactions or exchange coupling.

\subsubsection{Thermal analysis}

Thermogravimetric analysis was used to confirm clay modification by TBZ, surfactant and fungi. The increase of mass loss percentage and the appearance of new peaks in derivativethermogravimetric (DTg) curves at the temperature range of $200-500{ }^{\circ} \mathrm{C}$ were assigned to different steps of organic matter combustion (Table 2). The adsorption of TBZ in Mt sample promoted an increase of mass loss percentage of $2.0 \%$ in Mt-TBZ and the appearance of a new peak in DTg curve at $335^{\circ} \mathrm{C}$, assigned to fungicide combustion. This temperature was higher than that of pure $\mathrm{TBZ}\left(302{ }^{\circ} \mathrm{C}\right)$, indicating its interaction with the clay surface. ODTMA intercalation in the Mt interlayer produced a $7.7 \%$ increase of mass loss percentage accompanied by a new "desurfactant" peak at $291^{\circ} \mathrm{C}$, higher than that of each of the pure surfactants

Table 2

DTg peaks and mass loss percentage of organic combustion process $\left(200-500{ }^{\circ} \mathrm{C}\right)$.

\begin{tabular}{lll}
\hline Sample & DTg peak $\left({ }^{\circ} \mathrm{C}\right)$ & Mass loss percentage $(\%)$ \\
\hline Mt & n.a. & 0.8 \\
Mt-TBZ & 355 & 2.0 \\
Mt-Cu-TBZ & 302 & 3.0 \\
BMt & 255 & 19.8 \\
BMt-Cu & 251 & 15.8 \\
BMt-TBZ & 273 & 18.9 \\
BMt-Cu-TBZ & $269 ; 473(\mathrm{~s})$ & 23.5 \\
OMt & 291 & 7.7 \\
OMt-Cu & 280 & 7.2 \\
OMt-TBZ & $296 ; 350$ & 8.1 \\
OMt-Cu-TBZ & $274 ; 294$ & 8.2 \\
\hline
\end{tabular}

n.a.: not applicable; (s) shoulder. $\left(249^{\circ} \mathrm{C}\right)$ due to the oxidation of ODTMA chains electrostatically bonded to the siloxane surface. Finally, the fungi promoted an increase of mass loss percentage of $19.8 \%$, whereas the peaks observed were assigned to an overlapping of the combustion of biomass DTg at $255^{\circ} \mathrm{C}$.

Also, this technique allowed confirming the uptake of $\mathrm{Cu}^{2+}$ by the surfactant and biomass modified Mt samples. In all cases, the presence of $\mathrm{Cu}^{2+}$ induced a decrease of the organicdecomposition temperature in the $\mathrm{Cu}^{2+}$-loaded samples. This behaviour was explained in terms of the $\mathrm{Cu}^{2+}$ acting as a catalyst for organic matter combustion and confirming the metal-biomass and metal-TBZ interaction [44-46]. Related to this phenomenon, the increase of mass loss percentage in BMt-Cu was lower than that of the other samples, and this result was explained in terms of the catalytic activity of the copper cation as combustion initiates at a lower temperature.

\subsection{Leaching assays}

With the aim of studying the toxicity of the evaluated solids in view of their application in wastewater treatment, digestion and leaching experiments were performed, and the results are summarised in Table 3. After TBZ adsorption, more than $90 \%$ of the initial $\mathrm{Cu}^{2+}$ remained in all samples. The fact that almost $10 \%$ of initial $\mathrm{Cu}^{2+}$ was removed during the TBZ adsorption experiment suggested that there was an excess of $\mathrm{Cu}^{2+}$ in the adsorbents and probably a lower amount could be used to avoid its removal.

The leached $\mathrm{Cu}^{2+}$ and TBZ in Table 3 were calculated as a percentage of initial $\mathrm{Cu}^{2+}$ and TBZ loadings, respectively. A decrease of leached metal from $24 \%$ in $\mathrm{Mt}-\mathrm{Cu}$ to 9.7 and $9.3 \%$ in OMt-Cu and BMt-Cu samples, respectively, was found. The decrease of $\mathrm{Cu}^{2+}$ removed was assigned to the fact that in $\mathrm{Mt}-\mathrm{Cu}$ sample, $\mathrm{Cu}^{2+}$ was mostly bonded to permanent charge sites, while in BMt-Cu some $\mathrm{Cu}^{2+}$ was bonded to specific binding sites present in the biomass (see $s S-R M N$ \& EPR Section). A similar behaviour occurred in OMt-Cu sample, where ODTMA prevented the leaching of interlayer $\mathrm{Cu}^{2+}$ by diffusional and steric hindrance.

The presence of TBZ in the samples led to a further decrease in the percentage of leached $\mathrm{Cu}^{2+}$ from 24 to $0.9 \%$ in $\mathrm{Mt}-\mathrm{Cu}$ and MtCu-TBZ samples, respectively; from 9.7 to $2.4 \%$ in OMt-Cu and OMt-Cu-TBZ samples, respectively; and from 9.3 to $3.6 \%$ in BMt$\mathrm{Cu}$ and BMt-Cu-TBZ samples, respectively. A similar behaviour was found in desorption experiments of cysteine loaded onto $\mathrm{Cu}-$ rich montmorillonite [33]. In that case, the formation of a stable chelate-complex cysteine- $\mathrm{Cu}^{2+}$ prevented or retarded the migration of both contaminants (cysteine and $\mathrm{Cu}^{2+}$ ). This feature was not observed when $\mathrm{Na}^{+}$and $\mathrm{Ca}^{2+}$ were the interlayer ions, and was related to the greater tendency of $\mathrm{Cu}^{2+}$ to form stable complexes with the amino acid. The development of stable TBZ- $\mathrm{Cu}^{2+}$ complexes in the interlayer of the adsorbents would explain the decrease of leached $\mathrm{Cu}^{2+}$. Furthermore, it could be suggested that the different geometries adopted by the complexes in the interlayer (analysed in XRD Section) promoted different interaction energies with the siloxane layer, explaining the $\mathrm{Cu}^{2+}$ leaching $0.9 \%$ in $\mathrm{Mt}-\mathrm{Cu}-\mathrm{TBZ}$ sample and of around $3 \%$ in OMt-Cu-TBZ and BMt-Cu-TBZ samples.

Finally, leaching of TBZ was below the detection limit in all the samples $(0.0045 \mathrm{mg} / \mathrm{L})$, except for Mt-TBZ, suggesting that the modification of the clay by biomass or surfactant is recommended to avoid the later migration of the contaminants to soils or water.

\section{Conclusions}

From the results of this study, the following conclusions can be drawn. 
Adsorption isotherms were well fitted by Langmuir-Freundlich model. The $q_{\max }$ values were $14 \pm 2 \mathrm{mg} / \mathrm{g}$ for both Mt and OMt samples and $28 \pm 2 \mathrm{mg} / \mathrm{g}$ for BMt. These results showed that the presence of biomass in BMt sample enhanced thiabendazole adsorption due to the development of new binding sites, while the alkyl chain in OMt sample did not favour TBZ adsorption because the adsorption sites in this sample were the siloxane surface, specifically the permanent charge sites. The $q_{\max }$ values for the $\mathrm{Cu}^{2+}$-loaded materials doubled, being $28 \pm 2,27 \pm 2$ and $47 \pm 2 \mathrm{mg} / \mathrm{g}$ for Mt-Cu, OMt$\mathrm{Cu}$ and $\mathrm{BMt}-\mathrm{Cu}$, respectively, since the metal cation acted as a specific and high affinity TBZ adsorption site.

TBZ removal efficiency was $>95 \%$ for the $\mathrm{Cu}^{2+}$ samples, when an adsorbent dose $=1 \mathrm{~g} / \mathrm{L}$ was used, regardless of the adsorbent. When the adsorbent dose was decreased to $0.1 \mathrm{~g} / \mathrm{L}$, a more accurate TBZ removal efficiency was determined, following the order: $\mathrm{Mt}-\mathrm{Cu}>\mathrm{BMt}-\mathrm{Cu}>\mathrm{OMt}-\mathrm{Cu}$ samples. This behaviour was related to the metal content in the adsorbents and to the metal availability to exchange the local ligand (water) for TBZ. The highest TBZ removal efficiency found for $\mathrm{Mt}-\mathrm{Cu}$ sample compared to other samples at low adsorbent doses was assigned to its high amount of $\mathrm{Cu}^{2+}$ and its interlayer location. The intermediate adsorption behaviour for BMt sample was assigned to the lower availability of $\mathrm{Cu}^{2+}$ for the ligand exchange with TBZ, due to its bonding to the interlayer sites and to specific functional groups of the cellular wall. The OMt sample showed the lowest TBZ removal efficiency within the studied adsorbents and adsorbent doses, due to the occupancy of the interlayer sites by the ammonium cations, which did not favour the uptake of $\mathrm{Cu}^{2+}$ and then its interaction with TBZ.

From EPR and ss-RMN studies, it was not possible to determine the metal coordination sphere for the OMt-Cu sample; despite it was possible to identify the ligands involved in the uptake of copper ions for BMt-Cu and Mt-Cu. For BMt-Cu sample, the carbonyl carbon of the acetylated amino groups present in the polysaccharide (N-acetylglucosamine-like residues) together with the carbonyl group of carboxylic acid of amino acids or amide-type carbon of oligopeptides were mainly involved in the coordination of $\mathrm{Cu}^{2+}$ ions according with to ${ }^{13} \mathrm{C} \mathrm{CP}-\mathrm{MAS}$ spectrum. In the EPR experiments, the signal at $\mathrm{g}=2.12$ was associated with free hydrated $\mathrm{Cu}^{2+}$ ions or coordinated with hydroxyl groups and water molecules in the interlayer of the Mt structure in Mt-Cu and BMtCu samples.

The biomass, surfactant and $\mathrm{Cu}^{2+}$-Mt modifications developed in this study have potential use in water treatment. However, to apply them as adsorbents in real effluents, further work should be conducted to evaluate adsorption performance in real conditions and regeneration capabilities.

\section{Acknowledgments}

The authors acknowledge the funding provided by FONARSEC project, Nano FS-008/2010 and PICT-ANPCyT 2011-2690. GC, JLM and RMTS are members of CONICET, and MG, MO and GG acknowledge National Council of Scientific and Technical Research - CONICET, Argentina for their respectively fellowships.

\section{Appendix A. Supplementary data}

Supplementary data associated with this article can be found, in the online version, at http://dx.doi.org/10.1016/j.cej.2017.03.034.

\section{References}

[1] M. Amin, A.U. Malik, A.S. Khan, N. Javed, Potential of fungicides and plant activator for postharvest disease management in mangoes, Int. J. Agric. Biol. 13 (2011) 671-676.
[2] M. Groh, P. Blanche, Y. Calmus, L. Guillevin, Thiabendazole-induced acute liver failure requiring transplantation and subsequent diagnosis of polyarteritis nodosa, Clin. Exp. Rheumatol. 30 (2012) S107-S109.

[3] A. Kouras, A. Zouboulis, C. Samara, T. Kouimtzis, Removal of pesticides from aqueous solutions by combined physicochemical processes - The behaviour of lindane, Environ. Pollut. 103 (1998) 193-202, http://dx.doi.org/10.1016/ S0269-7491(98)00124-9.

[4] R. Zhu, Q. Chen, H. Liu, F. Ge, L. Zhu, J. Zhu, H. He, Montmorillonite as a multifunctional adsorbent can simultaneously remove crystal violet, cetyltrimethylammonium, and 2-naphthol from water, Appl. Clay Sci. 88-89 (2014) 33-38, http://dx.doi.org/10.1016/j.clay.2013.12.010.

[5] O. Hocine, M. Boufatit, A. Khouider, Use of montmorillonite clays as adsorbents of hazardous polluants, Desalination 167 (2004) 141-145, http://dx.doi.org/ 10.1016/j.desal.2004.06.122.

[6] L. Ma, Q. Chen, J. Zhu, Y. Xi, H. He, R. Zhu, Q. Tao, G.A. Ayoko, Adsorption of phenol and $\mathrm{Cu}(\mathrm{II})$ onto cationic and zwitterionic surfactant modified montmorillonite in single and binary systems, Chem. Eng. J. 283 (2016) 880888, http://dx.doi.org/10.1016/j.cej.2015.08.009.

[7] J.L. Marco-brown, M.M. Areco, R.M. Torres, S. Afonso, Colloids and Surfaces A : Physicochemical and Engineering Aspects Adsorption of picloram herbicide on montmorillonite : Kinetic and equilibrium studies, Colloids Surfaces A Physicochem. Eng. Asp. 449 (2014) 121-128, http://dx.doi.org/10.1016/ j.colsurfa.2014.02.038.

[8] C.H. Zhou, D. Zhang, D.S. Tong, L.M. Wu, W.H. Yu, S. Ismadji, Paper-like composites of cellulose acetate-organo-montmorillonite for removal of hazardous anionic dye in water, Chem. Eng. J. 209 (2012) 223-234, http:// dx.doi.org/10.1016/j.cej.2012.07.107.

[9] M.M.F. Silva, M.M. Oliveira, M.C. Avelino, M.G. Fonseca, R.K.S. Almeida, E.C. Silva, Filho, Adsorption of an industrial anionic dye by modified-KSFmontmorillonite: Evaluation of the kinetic, thermodynamic and equilibrium data, Chem. Eng. J. 203 (2012) 259-268, http://dx.doi.org/10.1016/j. cej.2012.07.009.

[10] Z. Gu, M. Gao, L. Lu, Y. Liu, S. Yang, Montmorillonite Functionalized with Zwitterionic Surfactant as a Highly Efficient Adsorbent for Herbicides, Ind. Eng. Chem. Res. 54 (2015) 4947-4955, http://dx.doi.org/10.1021/acs.iecr.5b00438.

[11] Y. Xi, Z. Ding, H. He, R.L. Frost, Structure of organoclays - An X-ray diffraction and thermogravimetric analysis study, J. Colloid Interface Sci. 277 (2004) 116120.

[12] M. Gamba, F.M. Flores, J. Madejová, R.M.T. Sánchez, Comparison of imazalil removal onto montmorillonite and nanomontmorillonite and adsorption surface sites involved: An approach for agricultural wastewater treatment Ind. Eng. Chem. Res. 54 (2015) 1529-1538, http://dx.doi.org/10.1021/ ie5035804.

[13] B. Lombardi, M. Baschini, R.M. Torres, Sánchez, Optimization of parameters and adsorption mechanism of thiabendazole fungicide by a montmorillonite of North Patagonia, Argentina, Appl. Clay Sci. 24 (2003) 43-50, http://dx.doi.org/ 10.1016/j.clay.2003.07.005.

[14] M.E. Roca Jalil, R.S. Vieira, D. Azevedo, M. Baschini, K. Sapag, Improvement in the adsorption of thiabendazole by using aluminum pillared clays, Appl. Clay Sci. 71 (2013) 55-63, http://dx.doi.org/10.1016/j.clay.2012.11.005.

[15] J.-M. Grevy, F. Tellez, S. Bernés, H. Nöth, R. Contreras, N. Barba-Behrens, Coordination compounds of thiabendazole with main group and transition metal ions, Inorganica Chim. Acta. 339 (2002) 532-542.

[16] H. Ennajih, H. Gueddar, A. El Kadib, R. Bouhfid, M. Bousmina, E.M. Essassi, Intercalation of nickel and cobalt thiabendazole complexes into montmorillonite, Appl. Clay Sci. 65-66 (2012) 139-142, http://dx.doi.org/ 10.1016/j.clay.2012.04.027.

[17] WHO World Health Organization, Guidelines for drinking-water quality, fourth ed., Geneva, 2011.

[18] J. Morton, J. Semrau, K. Hayes, An X-ray absorption spectroscopy study of the structure and reversibility of copper adsorbed to montmorillonite clay, Geochim. Cosmochim. Acta. 65 (2001) 2709-2722, S0016703701006330.

[19] M. El-Batouti, A.A. Zaghloul, M.T. Hanna, A kinetic study of the copper exchange reaction on a sodium-montmorillonite clay mineral in acetonitrile and dimethylformamide, J. Colloid Interface Sci. 180 (1996) 106-110, http:// dx.doi.org/10.1006/jcis.1996.0278.

[20] C.O. Ijagbemi, M.-H. Baek, D.-S. Kim, Montmorillonite surface properties and sorption characteristics for heavy metal removal from aqueous solutions, J. Hazard. Mater. 166 (2009) 538-546, http://dx.doi.org/10.1016/j. jhazmat.2008.11.085.

[21] D. Datta, H. Uslu, S. Kumar, Adsorptive separation of $\mathrm{Cu}^{2+}$ from an aqueous solution using trioctylamine supported montmorillonite, J. Chem. Eng. Data. 60 (2015) 3193-3200, http://dx.doi.org/10.1021/acs.jced.5b00413.

[22] H.P. He, J.G. Guo, X.D. Xie, J.L. Peng, Location and migration of cations in Cu2+ adsorbed montmorillonite, Environ. Int. 26 (2001) 347-352.

[23] S.T. Akar, T. Akar, Z. Kaynak, B. Anilan, A. Cabuk, Ö. Tabak, T. Gedikbey, Removal of copper (II) ions from synthetic solution and real wastewater by the combined action of dried Trametes versicolor cells and montmorillonite, Hydrometallurgy 97 (2009) 98-104.

[24] M.S. Olivelli, G.A. Curutchet, R.M. Torres, Sánchez, Uranium uptake by Montmorillonite-biomass complexes, Ind. Eng. Chem. Res. 52 (2013) 22732279, http://dx.doi.org/10.1021/ie301773p.

[25] A.P. Magnoli, L. Tallone, C.A.R. Rosa, A.M. Dalcero, S.M. Chiacchiera, R.M. Torres, Sanchez, Commercial bentonites as detoxifier of broiler feed contaminated with aflatoxin, Appl. Clay Sci. 40 (2008) 63-71, http://dx.doi. org/10.1016/j.clay.2007.07.007. 
[26] P.C. Tway, J.C. Love, Effects of excited-state prototropic equilibria on the fluorescence energies of benzimidazole and thiabendazole homologues, J. Phys. Chem. 86 (26) (1982) 5227-5230.

[27] V. Sandy, A. Maramis, A. Kurniawan, J. Ayucitra, S. Sunarso, Ismadji, Removal of copper ions from aqueous solution by adsorption using LABORATORIESmodified bentonite (organo-bentonite), Front. Chem. Sci. Eng. 6 (2012) 58-66, http://dx.doi.org/10.1007/s11705-011-1160-6.

[28] V. Guimarães, E. Rodríguez-Castellón, M. Algarra, F. Rocha, I. Bobos, Influence of $\mathrm{pH}$, layer charge location and crystal thickness distribution on $\mathrm{U}(\mathrm{VI})$ sorption onto heterogeneous dioctahedral smectite, J. Hazard. Mater. 317 (2016) 246-258, http://dx.doi.org/10.1016/j.jhazmat.2016.05.060.

[29] B.M. Fung, A.K. Khitrin, K. Ermolaev, An improved broadband decoupling sequence for liquid crystals and solids, J. Magn. Reson. 142 (2000) 97-101.

[30] Environmental Protection Agency (EPA), Method 1312: Synthetic precipitation leaching procedure, 1990 .

[31] M. Gamba, P. Ková, M. Pospí, R.M. Torres, Insight into thiabendazole interaction with montmorillonite and organically modified montmorillonites, Appl. Clay Sci. 137 (2017) 59-68, http://dx.doi.org/ 10.1016/j.clay.2016.12.001.

[32] S.M. Lee, D. Tiwari, Organo and inorgano-organo-modified clays in the remediation of aqueous solutions: An overview, Appl. Clay Sci. 59-60 (2012) 84-102, http://dx.doi.org/10.1016/j.clay.2012.02.006.

[33] M.F. Brigatti, C. Lugli, S. Montorsi, L. Poppi, Effects of exchange cations and layer-charge location on cysteine retention by smectites, Clays Clay Miner. 47 (1999) 664-671.

[34] A. Brtáňová, J. Madejová, V. Bizovská, P. Komadel, Utilization of near infrared spectroscopy for studying solvation properties of $\mathrm{Cu}$-montmorillonites, Spectrochim. Acta - Part A Mol. Biomol. Spectrosc. 123 (2014) 385-391, http://dx.doi.org/10.1016/j.saa.2013.12.022.

[35] H. Joseph-Ezra, A. Nasser, U. Mingelgrin, Surface interactions of pyrene and phenanthrene on Cu-montmorillonite, Appl. Clay Sci. 95 (2014) 348-356, http://dx.doi.org/10.1016/j.clay.2014.04.037.

[36] R.Y. Rasente, J.C. Imperiale, J.M. Lázaro-Martínez, L. Gualco, R. Oberkersch, A Sosnik, G.C. Calabrese, Dermatan sulfate/chitosan polyelectrolyte complex with potential application in the treatment and diagnosis of vascular disease Carbohydr. Polym. 144 (2016) 362-370, http://dx.doi.org/10.1016 j.carbpol.2016.02.046.
[37] H. Kono, S. Yunoki, T. Shikano, M. Fujiwara, T. Erata, M. Takai, CP/MAS ${ }^{13} \mathrm{C}$ NMR study of cellulose and cellulose derivatives. 1. Complete assignment of the $\mathrm{CP} /$ MAS ${ }^{13} \mathrm{C}$ NMR spectrum of the native cellulose, J. Am. Chem. Soc. 124 (2002) 7506-7511, http://dx.doi.org/10.1021/ja010704o.

[38] J.M. Lázaro-Martínez, G.A. Monti, A.K. Chattah, Insights into the coordination sphere of copper ion in polymers containing carboxylic acid and azole groups, Polymer (United Kingdom) 54 (2013) 5214-5221, http://dx.doi.org/10.1016/j. polymer.2013.07.036.

[39] V. Lillo, J.R. Galán-Mascarós, Transition metal complexes with oligopeptides: Single crystals and crystal structures, Dalt. Trans. 43 (2014) 9821-9833, http:// dx.doi.org/10.1039/c4dt00650j.

[40] J.M. Lázaro-Martínez, E. Rodríguez-Castellón, D. Vega, G.A. Monti, A.K. Chattah, Solid-state studies of the crystalline/amorphous character in linear poly (ethylenimine hydrochloride) $(\mathrm{PEI} \cdot \mathrm{HCl})$ polymers and their copper Complexes, Macromolecules 48 (2015) 1115-1125, http://dx.doi.org/10.1021/ma5023082.

[41] L. Heller-Kallai, C. Mosser, Migration of $\mathrm{Cu}$ ions in $\mathrm{Cu}$ montmorillonite heated with and without alkali halides, Clays Clay Miner. 43 (1995) 738-743, http:// dx.doi.org/10.1346/CCMN.1995.0430610.

[42] J.P. Donoso, C.J. Magon, J.F. Lima, O.R. Nascimento, E. Benavente, M. Moreno, G. Gonzalez, Electron paramagnetic resonance study of copper-ethylenediamine complex ion intercalated in bentonite, J. Phys. Chem. C 117 (2013) 2404224055, http://dx.doi.org/10.1021/jp408658d.

[43] A.C. Rizzi, N.I. Neuman, P.J. González, C.D. Brondino, EPR as a tool for study of isolated and coupled paramagnetic centers in coordination compounds and macromolecules of biological interest, Eur. J. Inorg. Chem. 2016 (2016) 192207, http://dx.doi.org/10.1002/ejic.201501111.

[44] D. Vamvuka, E. Karouki, S. Sfakiotakis, P. Salatino, Gasification of waste biomass chars by carbon dioxide via thermogravimetry-effect of catalysts, Combust. Sci. Technol. 184 (2012) 64-77, http://dx.doi.org/10.1080/ 00102202.2011 .618152$.

[45] A. Nzihou, B. Stanmore, The fate of heavy metals during combustion and gasification of contaminated biomass-A brief review, J. Hazard. Mater. 256257 (2013) 56-66, http://dx.doi.org/10.1016/j.jhazmat.2013.02.050.

[46] R. Azargohar, S. Nanda, J.A. Kozinski, A.K. Dalai, R. Sutarto, Effects of temperature on the physicochemical characteristics of fast pyrolysis biochars derived from Canadian waste biomass, Fuel 125 (2014) 90-100, http:// dx.doi.org/10.1016/j.fuel.2014.01.083. 